\title{
pÿSelective Aerobic Oxidation of Alcohols with NO3 Activated Nitroxyl Radical/Manganese Catalyst System
}

\section{Lagerblom, Kalle}

2018-07-09

Lagerblom , K, Keskiväli , J , Parviainen , A , Mannisto , J \& Repo , T 2018 , ' Selective pÿAerobic Oxidation of Alcohols with NO3 Activated Nitroxyl Radical/Manganese Catalyst System ' , ChemCatChem , vol. 10 , no. 13 , pp. 2908-2914 . https://doi.org/10.1002/cctc.201800438

http://hdl.handle.net/10138/303797

https://doi.org/10.1002/cctc.201800438

unspecified

acceptedVersion

Downloaded from Helda, University of Helsinki institutional repository.

This is an electronic reprint of the original article.

This reprint may differ from the original in pagination and typographic detail.

Please cite the original version. 
Heterogeneous \& Homogeneous \& Bio- \& NanoCHEMCATCHEM CATALYSIS

\section{Accepted Article}

Title: Selective Aerobic Oxidation of Alcohols with NO3- Activated Nitroxyl Radical/Manganese Catalyst System

Authors: Kalle Lagerblom, Juha Keskiväli, Arno Parviainen, Jere Mannisto, and Timo Juhani Repo

This manuscript has been accepted after peer review and appears as an Accepted Article online prior to editing, proofing, and formal publication of the final Version of Record (VoR). This work is currently citable by using the Digital Object Identifier (DOI) given below. The VoR will be published online in Early View as soon as possible and may be different to this Accepted Article as a result of editing. Readers should obtain the VoR from the journal website shown below when it is published to ensure accuracy of information. The authors are responsible for the content of this Accepted Article.

To be cited as: ChemCatChem 10.1002/cctc.201800438

Link to VoR: http://dx.doi.org/10.1002/cctc.201800438 
WILEY-VCH

\title{
Selective Aerobic Oxidation of Alcohols with $\mathrm{NO}_{3}{ }^{-}$Activated Nitroxyl Radical/Manganese Catalyst System
}

\author{
Kalle Lagerblom, Juha Keskiväli, Arno Parviainen, Jere Mannisto and Timo Repo*[a]
}

\begin{abstract}
Homogeneous $\mathrm{Mn}\left(\mathrm{NO}_{3}\right)_{2} / 2,2,6,6$-tetramethylpiperidin-1$\mathrm{yl}) 0 x y \mathrm{l} / 2$-picolinic acid catalyst system has been found highly active and versatile for the selective aerobic oxidation of alcohols $(2,2,6,6$ tetramethylpiperidin-1-yl)oxyl = TEMPO, 2-picolinic acid = PyCOOH). The catalytic method enables near quantitative conversion of various primary alcohols to the respective aldehydes using a very simple reaction setup and workup. This study presents findings on the catalyst stability and mechanisms of deactivation. The results show that $\mathrm{NO}_{3}{ }^{-}$plays a crucial catalytic role in the reaction as a source of oxygen activating $\mathrm{NO}_{x}$ species. Yet, disproportionation of $\mathrm{NO}_{3}{ }^{-}$to the volatile $\mathrm{NO}_{2}$ during the reaction leads to catalyst deactivation under open air conditions. Catalyst deactivation through this route can be overcome by adding a catalytic amount of nitrate salt, for example $\mathrm{NaNO}_{3}$ into the reaction. This stabilizes the $\mathrm{Mn}\left(\mathrm{NO}_{3}\right)_{2} / \mathrm{TEMPO} / \mathrm{PyCOOH}$ catalyst and enables oxidation of various primary alcohols to the respective aldehydes using low catalyst loadings under ambient conditions. Secondary alcohols can be oxidized with a modified catalyst utilizing sterically accessible nitroxyl radical 9-azabicyclo[3.3.1]nonane $\mathrm{N}$-oxyl (ABNO) instead of TEMPO. At the end of the alcohol oxidation, pure carbonyl products and reusable catalyst can be recovered simply by extracting with organic solvent and dilute aqueous acid, followed by evaporation of both phases.
\end{abstract}

\section{Introduction}

The selective oxidation of alcohols to carbonyl compounds is one of the most used transformations in organic chemistry. ${ }^{[1]}$ Traditionally, this reaction is performed using stoichiometric oxidants, such as $\mathrm{CrO}_{3},{ }^{[2,3]} \mathrm{MnO}_{2},{ }^{[4,5]}$ hypervalent iodine ${ }^{[6,7]}$ or activated DMSO. ${ }^{[8-10]}$ These reagents are all costly and their use in industrial-scale reactions result in large quantities of hazardous waste. Cost efficient and environmentally benign catalytic approaches employing $\mathrm{O}_{2}{ }^{[11-16]}$ or $\mathrm{NaOCI}^{[17-21]}$ as oxidant have lately received great attention to ease the environmental and economic burden of alcohol oxidation. Especially aerobic oxidation has gained prominence due to its advantages, such as abundance of $\mathrm{O}_{2}$ in the atmosphere and water as the only byproduct. The selective oxidation of alcohols to the respective carbonyl compounds using $\mathrm{O}_{2}$ as the terminal oxidant has been demonstrated using catalysts based on noble metals, such as

[a] K. Lagerblom, J. Keskiväli, Dr. A. Parviainen, J. Mannisto and Prof. Dr. T. Repo

Department of Chemistry

Faculty of Science

A. I. Virtasen aukio 1, 00014 University of Helsinki P.O. Box 55

Finland

E-mail: timo.repo@helsinki.fi

Supporting information for this article is given via a link at the end of the document.

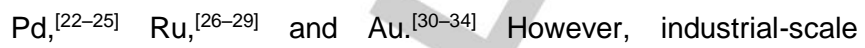
processes utilizing aerobic oxidation reactions have been limited due to restricted substrate scopes, ${ }^{[35,36]}$ frequent use of halogenated solvents ${ }^{[37-41]}$ and safety concerns related to use of flammable reagents and solvents under high pressures of $\mathrm{O}_{2}{ }^{[42]}$ On the other hand, when selecting oxidation methods for small scale synthesis in laboratory, practical aspects are most often emphasized. ${ }^{[43,44]}$ In this respect, it is not surprising that simple traditional uncatalyzed reactions are often preferred over the catalytic aerobic reactions, averting complex catalyst syntheses and laborious use of special equipment, such as autoclaves and $\mathrm{O}_{2}$ cylinders. ${ }^{[26,45-50]}$ Accordingly, there is a high demand for aerobic alcohol oxidation methods that utilize commonly used chemicals as catalysts, provide sufficient reactivity under low pressures of dilute $\mathrm{O}_{2}: \mathrm{N}_{2}$ mixtures and have broad substrate scopes.

In the search of new aerobic oxidation methods for alcohols, promising results have been obtained with the combined use of nitroxyl radicals, such as (2,2,6,6-tetramethylpiperidin-1-yl)oxyl (TEMPO) and first-row transition metals, such as $\mathrm{Cu}$ and Fe. ${ }^{[51-58]}$ Recently, we reported that a highly active alcohol oxidation catalyst can be easily prepared by combining TEMPO with $\mathrm{Mn}\left(\mathrm{NO}_{3}\right)_{2}$ and 2-picolinic acid $(\mathrm{PyCOOH})$ in situ. ${ }^{[59]}$ This catalyst system is straightforward and practical to use and it enables selective conversion of various primary alcohols incorporating aliphatic, allylic, benzylic and heteroaromatic structures to the respective aldehydes under ambient air at room temperature. Also, secondary alcohols are amenable to oxidation to ketones by simply replacing TEMPO with sterically more accessible 9azabicyclo[3.3.1]nonane $N$-oxyl (ABNO). The oxidized products can be isolated simply via extraction using organic solvents and the reaction has shown to be tolerant with alcohols containing various types of functionalities. Despite of these benefits, the above Mn-catalyst exhibits the following limitations: catalytic activity is low and high catalyst loadings have to be utilized to achieve complete substrate conversion (4-7.5 mol\% of $\mathrm{Mn}\left(\mathrm{NO}_{3}\right)_{2}$, TEMPO and $\mathrm{PyCOOH}$ ); catalyst stability has not been studied and recycling protocol has not been developed for the catalyst.

Herein, we report a markedly improved catalyst system, that enables the selective aerobic oxidation of alcohols using low loading of $\mathrm{Mn}\left(\mathrm{NO}_{3}\right)_{2}$ and TEMPO. We also report a highly practical recycling protocol for the catalyst along with our intriguing findings on catalyst stability and mechanisms of deactivation.

\section{Results and Discussion}

\section{Initial studies}

The study was initiated by investigating the effect of catalyst loading on oxidation of 5-hydroxymethyl furfural (1a, HMF) to 2,6diformylfuran (2a, DFF) with $\mathrm{Mn}\left(\mathrm{NO}_{3}\right)_{2} / \mathrm{TEMPO} / \mathrm{PyCOOH}$ catalyst. 
HMF was chosen as a model substrate because it is readily available through dehydration of biomass-based hexoses, and the target compound, DFF, is a versatile platform chemical having numerous potential applications in the industry. ${ }^{[60-63]}$ For example, DFF can be used as a starting material in the synthesis of resins, binders, sealants, organic conductors and fungicides. ${ }^{[64-68]} \mathrm{HMF}$ oxidations were conducted using 1, 2, 3 and $10 \mathrm{~mol} \%$ catalyst loadings under ambient conditions and progression of each reaction was followed for 180 minutes with off-line GC analysis (Figure 1). With $1 \mathrm{~mol} \%$ catalyst loading, the oxidation of HMF started rapidly, affording DFF in $8 \%$ yield after the first 5 minutes. However, the reaction rate decreased sharply after the first 10 minutes, presumably due to catalyst deactivation and only $15 \%$ DFF yield was achieved during the 180 min observation period. The experiment conducted with 2 mol\% catalyst loading resulted in faster initial HMF oxidation and slower catalyst deactivation, resulting in $46 \%$ DFF yield after $180 \mathrm{~min}$. The use of larger catalyst loadings improved the conversion of HMF to DFF even further. With $3 \mathrm{~mol} \%$ of catalyst, full conversion of HMF and DFF yield of $95 \%$ was recorded after $40 \mathrm{~min}$. When the highest catalyst loading of $10 \mathrm{~mol} \%$ was used, the reaction was even faster. It consumed all of the HMF in 20 min and resulted in 95\% DFF yield. indeed $\mathrm{NO}_{2}$. In this light, it seems plausible that acid induced conversion of $\mathrm{NO}_{3}{ }^{-}$to $\mathrm{NO}_{2}$ and evaporation of the later might contribute to the rapid catalyst deactivation, clearly observed during the HMF oxidations with the low 1 and 2 mol\% catalyst loadings above.

$4 \mathrm{HNO}_{3} \rightleftharpoons 4 \mathrm{NO}_{2}+2 \mathrm{H}_{2} \mathrm{O}+\mathrm{O}_{2}$

$2 \mathrm{NO}_{2}+\mathrm{H}_{2} \mathrm{O} \rightleftharpoons \mathrm{HNO}_{3}+\mathrm{HNO}_{2}$

According to current mechanistic understanding, the presence of $\mathrm{NO}_{3}{ }^{-}$is crucially important in the $\mathrm{Mn}\left(\mathrm{NO}_{3}\right)_{2} / \mathrm{TEMPO} / \mathrm{PyCOOH}$-catalyzed aerobic alcohol oxidation (Scheme 1). ${ }^{[59]}$ It acts as a source of oxygen activating $\mathrm{NO}_{\mathrm{x}}$ species, which oxidizes $\mathrm{Mn}^{\prime \prime}$ to $\mathrm{Mn}^{\text {III }}$ (Scheme 1, steps I \& II). Accordingly, if $\mathrm{NO}_{3}$ - concentration is reduced, the reaction slows down as oxidation of $\mathrm{Mn}^{\prime \prime}$ to $\mathrm{Mn}^{\text {III }}$ is impeded. As a consequence, oxidation of hydroxylamine TEMPOH back to TEMPO by $\mathrm{Mn}^{\mathrm{III}}$ is hindered (step III). This, in turn, leads to depletion of TEMPO, which forms the active oxidant $\mathrm{TEMPO}^{+}$and $\mathrm{TEMPOH}$ through acid induced disproportionation (Step IV). Eventually, alcohol oxidation cannot occur (step V), as all TEMPO+ has been reduced to TEMPOH through reaction with alcohol.

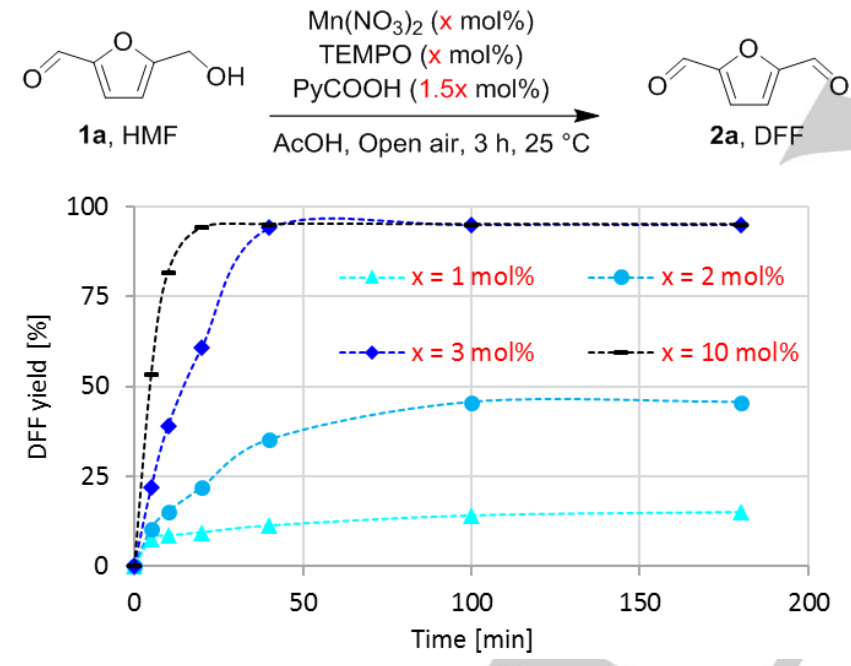

Figure 1. The effect of $\mathrm{Mn}\left(\mathrm{NO}_{3}\right)_{2} / \mathrm{TEMPO} / \mathrm{PyCOOH}$ catalyst loading on the aerobic oxidation of HMF to DFF.

During the oxidation of HMF with the highest, $10 \mathrm{~mol} \%$ catalyst amount, orange gas was detected in the headspace of the reaction. This suggested the presence of $\mathrm{NO}_{2}$, which is known to from $\mathrm{NO}_{3}^{-}$under the acidic reaction conditions, according to equation (1). ${ }^{[69]}$ To identify the gas, it was trapped into an alkaline water solution, where the $\mathrm{NO}_{2}$ would disproportionate to $\mathrm{NO}_{3}{ }^{-}$and $\mathrm{NO}_{2}{ }^{-}$anions according to equation (2). ${ }^{[70,71]}$ From this solution, the presence of $\mathrm{NO}_{3}^{-}$and $\mathrm{NO}_{2}^{-}$was investigated by classical qualitative analysis using diphenylamine and permanganate tests respectively (See SI for details). ${ }^{[72,73]}$ Both tests turned out positive, confirming that $\mathrm{NO}_{3}{ }^{-}$and $\mathrm{NO}_{2}^{-}$were present in the alkaline aqueous solution and that the orange gas over the reaction was

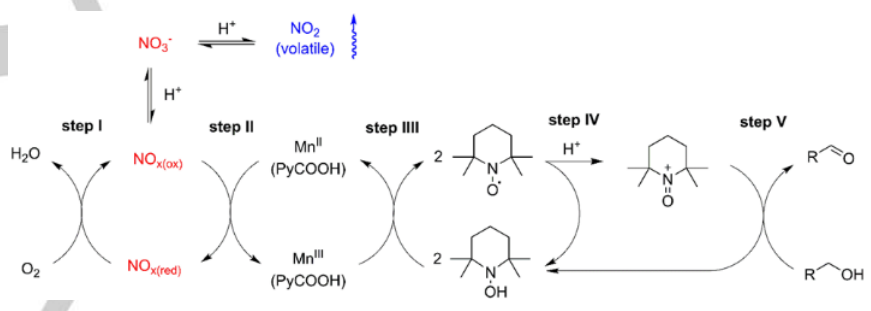

Scheme 1. Proposed mechanism for the aerobic oxidation of alcohols with $\mathrm{Mn}\left(\mathrm{NO}_{3}\right)_{2} / \mathrm{TEMPO} / \mathrm{PyCOOH}$ catalyst system, wherein the crucial role of $\mathrm{NO}_{3}{ }^{-}$is illustrated with red color together with $\mathrm{NO}_{2}$ evaporation in blue color.

The effect of added $\mathrm{NO}_{3}$ - on the catalytic activity was studied by oxidizing HMF with 1, 2, 3 and 10 mol\% catalyst loadings in the presence of $\mathrm{NaNO}_{3}$ (2 mol\%) (Figure 2). Evidently, the presence of added $\mathrm{NaNO}_{3}$ had a positive effect on catalytic activity. The significance of added $\mathrm{NaNO}_{3}$ was especially clear in the reactions performed using $1 \mathrm{~mol} \%$ and $2 \mathrm{~mol} \%$ catalyst loadings, as the catalyst lifetime was now significantly increased from the initial experiments performed without $\mathrm{NaNO}_{3}$. At the end of the reactions performed with 1 and 2 mol\% catalyst loadings DFF yields of $65 \%$ and $95 \%$ were recorded, respectively. In comparison, the use of same catalyst amounts resulted in only $15 \%$ and $46 \%$ DFF yields when $\mathrm{NaNO}_{3}$ additive was not included in the reaction. The presence of $\mathrm{NaNO}_{3}$ had less prominent effect on reaction outcome with higher catalyst loadings (3 and 10 mol\%) as sufficient $\mathrm{NO}_{3}{ }^{-}$concentration was already achieved in the initial experiments conducted without added $\mathrm{NaNO}_{3}$. 


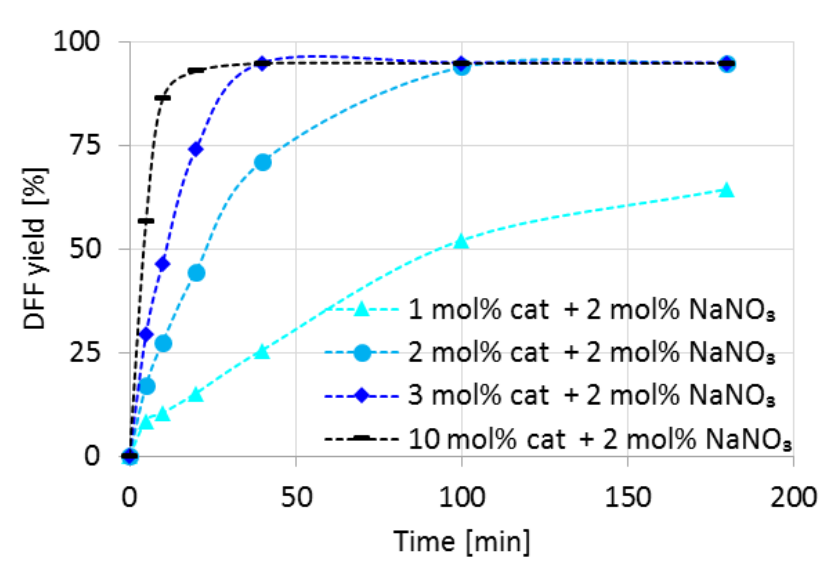

Figure 2. $\mathrm{NaNO}_{3}$ enhanced aerobic oxidation of $\mathrm{HMF}$ to DFF with $\mathrm{Mn}\left(\mathrm{NO}_{3}\right)_{2} / \mathrm{TEMPO} / \mathrm{PyCOOH}$ catalyst.

Upon discovering the positive effect of $\mathrm{NaNO}_{3}$ addition on catalyst performance, other additives containing nitrate and nitrite anions were studied as the catalyst activators. For this purpose, a series of HMF oxidations was conducted with $1 \mathrm{~mol} \%$ loading of $\mathrm{Mn}\left(\mathrm{NO}_{3}\right)_{2} / \mathrm{TEMPO} / \mathrm{PyCOOH}$ in the presence of $2 \mathrm{~mol} \%$ of selected nitrate and nitrite sources (Figure 3 ). The control reaction, performed in the absence of additives, resulted in $16 \% \mathrm{HMF}$ conversion and $15 \%$ DFF yield. Over three-fold increase in reactivity was achieved with the nitrate additives, resulting in 68\%70 HMF conversions and 65-67\% DFF yields. Also addition on nitrite salts clearly activated the catalyst, although resulting in slightly lower $57-61 \%$ HMF conversions and 54\%- 58\% DFF yields than obtained with nitrate additives. To see if the presence of $\mathrm{Na}^{+}$cation affects reactivity, addition of $\mathrm{CH}_{3} \mathrm{COONa}$ was tried, but it had little effect on the reaction outcome, leading to $21 \%$ HMF conversion and 19\% DFF yield. These results indicate that the presence of nitrates and nitrites in the reaction has a beneficial effect on catalyst activity, nitrates being superior to nitrites, while the counter cation of the salt has no notable effect.

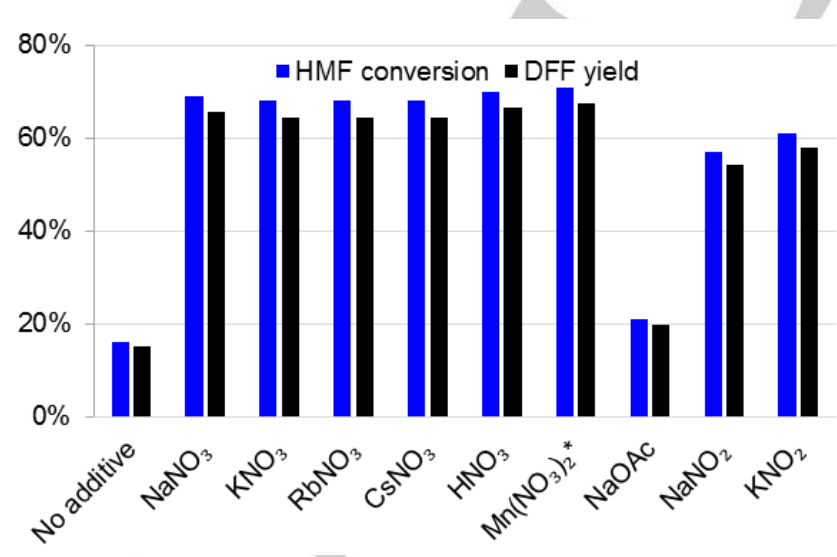

Figure 3. The effect of different nitrates and nitrites (2 mol\%) to catalytic oxidation of $\mathrm{HMF}$ with $\mathrm{Mn}\left(\mathrm{NO}_{3}\right)_{2} / \mathrm{TEMPO} / \mathrm{PyCOOH}(1 / 1.5 / 1 \mathrm{~mol} \%)$ catalyst under ambient conditions. Reaction time $3 \mathrm{~h} .{ }^{*} 1 \mathrm{~mol} \%$ of $\mathrm{Mn}\left(\mathrm{NO}_{3}\right)_{2}$
To study the effect of nitrate amount on catalyst activity, a series of HMF oxidations was conducted with $1 \mathrm{~mol} \%$ of $\mathrm{Mn}\left(\mathrm{NO}_{3}\right)_{2} / \mathrm{TEMPO} / \mathrm{PyCOOH}$ catalyst and varied amount (0-15 mol\%) of $\mathrm{NaNO}_{3}$ and $\mathrm{HNO}_{3}$ (Figure 4). The results revealed that, the DFF yields were steadily increased from $15 \%$ to $\geq 95 \%$ when loading of $\mathrm{NaNO}_{3}$ was increased from $0 \mathrm{~mol} \%$ to $4 \mathrm{~mol} \%$ or higher. At the same time, HMF conversions were increased from $16 \%$ to $>99 \%$ (SI Figure S1). Interestingly, addition of $\mathrm{HNO}_{3}$ resulted in similar catalyst activation with small amounts (1-4 mol\%), but decreasing DFF yields were recorded with higher $\mathrm{HNO}_{3}$ amounts ( $\geq 6 \mathrm{~mol} \%$ ) due to decreasing substrate conversion. Evidently, excessive acidity of the reaction solution hampers the catalytic activity. Presumably, the loss of catalytic activity is caused by accelerated conversion of $\mathrm{NO}_{3}{ }^{-}$to volatile $\mathrm{NO}_{2}$ under highly acidic conditions, according to equation (1). ${ }^{[69]}$ The increased proton concentration might also alter the coordination sphere of the redox active $\mathrm{Mn}$-center, leading to reduced activity. ${ }^{[59]}$ According to these results, a neutral nitrate source, such as $\mathrm{NaNO}_{3}$, should be preferred over $\mathrm{HNO}_{3}$ to enhance catalytic performance.

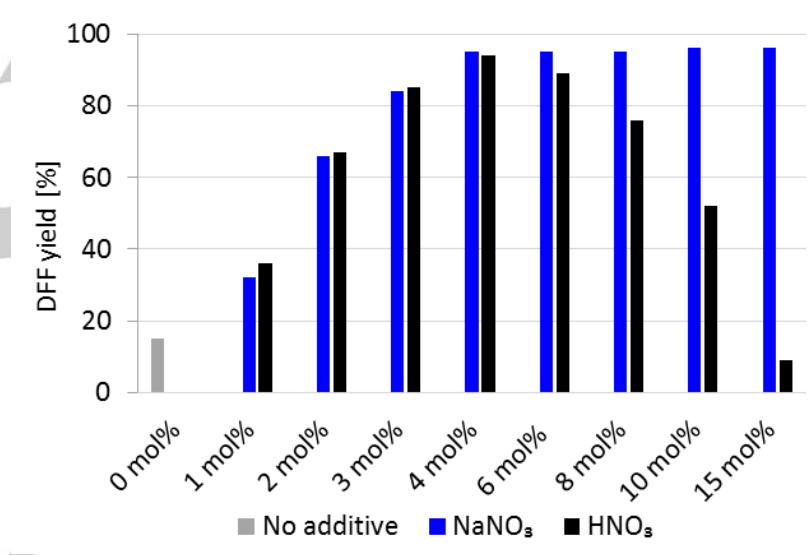

Figure 4. The effect of $\mathrm{NaNO}_{3}$ and $\mathrm{HNO}_{3}$ amount on $\mathrm{DFF}$ yield obtained through aerobic oxidation of $\mathrm{HMF}$ with $\mathrm{Mn}\left(\mathrm{NO}_{3}\right)_{2} / \mathrm{TEMPO} / \mathrm{PyCOOH}(1 / 1.5 / 1 \mathrm{~mol} \%)$ catalyst under ambient conditions. Reaction time $3 \mathrm{~h}$.

\section{Reaction scope}

Earlier, we demonstrated that $\mathrm{Mn}\left(\mathrm{NO}_{3}\right)_{2} / \mathrm{TEMPO} / \mathrm{PyCOOH}$ catalyst can be used for oxidation of wide variety of primary alcohols. ${ }^{[59]}$ However, the method required using high loadings of $\mathrm{Mn}\left(\mathrm{NO}_{3}\right)_{2}$, TEMPO and $\mathrm{PyCOOH},(4-7.5 \mathrm{~mol} \%$ each) to achieve complete alcohol conversions. Based on the mechanistic insights obtained from the HMF oxidation experiments presented herein, it seemed plausible that oxidation of various primary alcohols could be achieved using significantly lower amount of $\mathrm{Mn}\left(\mathrm{NO}_{3}\right)_{2} / \mathrm{TEMPO} / \mathrm{PyCOOH}$ catalyst if $\mathrm{NaNO}_{3}$ was added into the reaction to stabilize the catalyst. To test this hypothesis, a series of oxidation experiments with different substrates was conducted (Table 1). Heteroaromatic (1b), benzylic, (1c, 1d) aliphatic (1e, 1f) and allylic $(\mathbf{1 g}, \mathbf{1 h})$ primary alcohols were all smoothly converted to the respective aldehydes (2b-2h) using just $2 \mathrm{~mol} \%$ of $\mathrm{Mn}\left(\mathrm{NO}_{3}\right)_{2} / \mathrm{TEMPO} / \mathrm{PyCOOH}$ catalyst in the presence of $6 \mathrm{~mol} \%$ 
of $\mathrm{NaNO}_{3}$, under ambient conditions (Table 1, method A). Over $99 \%$ conversion was achieved with all of the above substrates within $4 \mathrm{~h}$, after which, pure aldehydes $\mathbf{2 b}-\mathbf{2 e}, \mathbf{2 g}$ and $\mathbf{2 h}$ could be recovered from the reaction solution by simple extraction with ether and water, followed by evaporation of the organic phase. Flash column chromatography was only conducted to purify $\mathbf{2 f}$.

As oxidation of substrates bearing unconjugated C-C double bonds, benzylic ethers and $\mathrm{C}-\mathrm{C}$ triple bonds with $\mathrm{Mn}\left(\mathrm{NO}_{3}\right)_{2} / \mathrm{TEMPO} / \mathrm{PyCOOH}$ catalyst results in side reactions at room temperature, oxidation of citronellol (1i), 3-benzyloxy-1propanol (1j) and 3-phenyl-2-propyn-1-ol (1k) was conducted at $16^{\circ} \mathrm{C}$ using balloon of $\mathrm{O}_{2}$ over the reaction (Table 1, method B). ${ }^{[59]}$ Under these conditions, $79-83 \%$ substrate conversions were achieved and aldehydes $\mathbf{2 i}-\mathbf{2} \mathbf{k}$ could be recovered in $71-76 \%$ yields.

Previous studies have showed that secondary alcohols are oxidized sluggishly with TEMPO-based catalysts. ${ }^{[1,18]}$ The unsatisfactory performance of these catalysts with secondary alcohols has been attributed to steric crowding around the alcohol a-hydrogen, which impedes the rate-determining hydride abstraction by sterically hindered oxoammonium ions like TEMPO+. ${ }^{[16,57]}$ Oxidation rates of secondary alcohols are generally increased notably when sterically less hindered nitroxyl radicals, such as such as $A B N O$ are used as catalyst, instead of TEMPO. ${ }^{[74]}$ Accordingly, oxidation of diphenyl methanol (11), 2octanol (1m) and borneol (1n) was conducted using $\mathrm{NaNO}_{3}$ enhanced $\mathrm{Mn}\left(\mathrm{NO}_{3}\right)_{2} / \mathrm{ABNO} / \mathrm{PyCOOH}$ catalyst system under ambient conditions (Table 1, Method C). This resulted in $>99 \%$ alcohol conversions and ketones $\mathbf{2 l}-\mathbf{2 n}$ could be isolated in excellent $94-98 \%$ yields by straightforward extraction with ether and water, followed by evaporation of the organic phase.

In order to see how significant impact addition of $\mathrm{NaNO}_{3}$ has on the catalyst activity, oxidation of alcohols $\mathbf{1} \mathbf{b}-\mathbf{1} \mathbf{n}$ was also conducted in the absence of $\mathrm{NaNO}_{3}$ (Table 1). On average, this resulted in $59 \%$ lower substrate conversion and $60 \%$ lower product yield compared to the results obtained in the presence of $\mathrm{NaNO}_{3}$. When $\mathrm{NaNO}_{3}$ was used to stabilize the catalyst, alcohol oxidations generally reached $>99 \%$ conversion and formation of side products was negligible. However, with few substrates (1e, $\mathbf{1 f}$ and $\mathbf{1 k}$ ) the reaction halted before $99 \%$ alcohol conversion was reached. Gratifyingly, these reactions could be restarted by adding another 6 mol\% batch of $\mathrm{NaNO}_{3}$ after initial stalling of the reaction. This method for re-activating the catalyst is worth noting if one uses the catalyst systems described herein for alcohol oxidation and the reaction stops progressing prior complete substrate conversion is achieved.

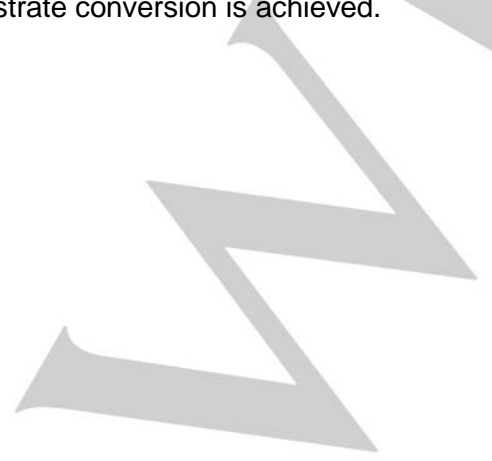

Table 1. Substrate scope of the aerobic oxidation of alcohols. ${ }^{[a]}$

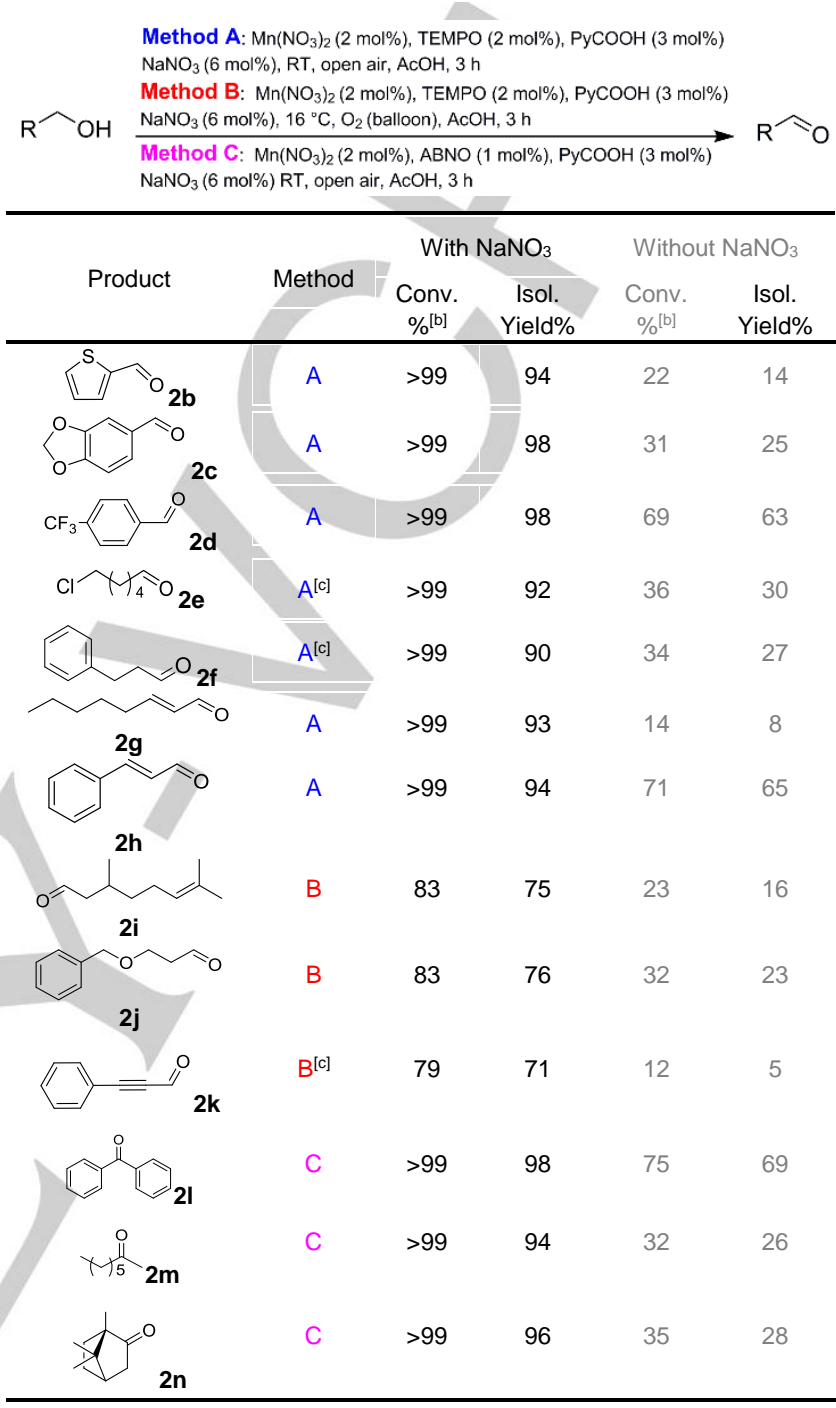

[a] Conditions: substrate $(2 \mathrm{mmol}), \mathrm{AcOH}(4 \mathrm{ml}), 800 \mathrm{rpm}$ stirring, open test tube. [b] Conversion determined using GC-FID with acetophenone as internal standard. [c] 12 mol\% $\mathrm{NaNO}_{3}$.

\section{Catalyst recycling}

Recyclability of $\mathrm{Mn}\left(\mathrm{NO}_{3}\right)_{2} / \mathrm{TEMPO} / \mathrm{PyCOOH} / \mathrm{NaNO}_{3}$ catalyst was examined by using benzyl alcohol (10) oxidation as a model reaction. It turned out, that the catalyst could be easily recycled by the following extractive treatment: upon completion of the alcohol oxidation, the reaction solution was extracted with diethyl ether and $1 \mathrm{M} \mathrm{HCl}$, in order to dissolve benzaldehyde (20) into the organic phase and the catalyst into the aqueous phase. The catalyst was recovered from the aqueous phase by evaporation in vacuo. A subsequent run was started by dissolving the recovered solid catalyst, fresh $\mathrm{NaNO}_{3}$ and a new batch of 10 into glacial $\mathrm{AcOH}$. By following this procedure, the catalyst was used successfully for five consecutive 10 oxidations (Figure 5). After the fifth use, substrate conversion of $80 \%$ was still recorded, showing that the catalyst is recyclable with minor decrease in 
activity. In contrast, if fresh $\mathrm{NaNO}_{3}$ was not added between subsequent uses of the catalyst, alcohol conversion declined sharply already after the first use, resulting in only $4 \%$ conversion during the second run (SI Figure S2). These observations further support the mechanistic insight about $\mathrm{NO}_{3}{ }^{-}$loss as the main route for catalyst deactivation that can be easily overcome by adding a catalytic amount of $\mathrm{NaNO}_{3}$ into the reaction.

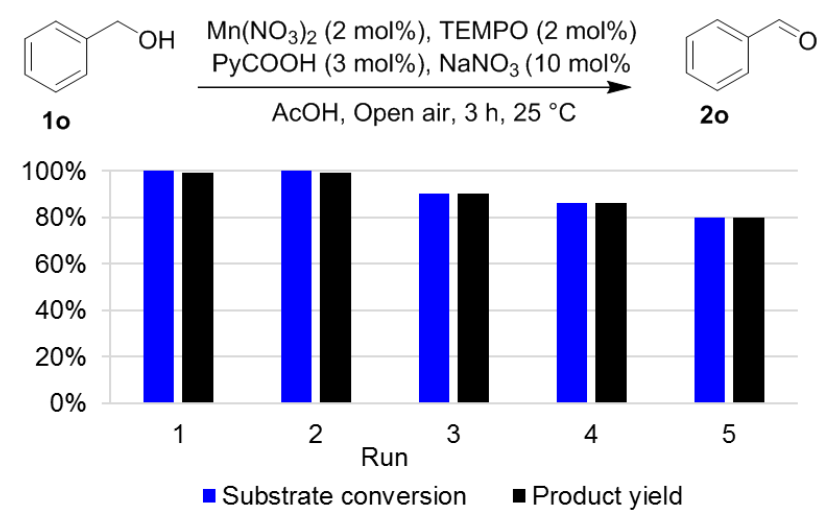

Figure 5. Oxidation of benzyl alcohol to benzaldehyde with recycled $\mathrm{Mn}\left(\mathrm{NO}_{3}\right)_{2} / \mathrm{PyCOOH} / \mathrm{TEMPO} / \mathrm{NaNO}_{3}$ catalyst.

\section{Conclusions}

This study shows that $\mathrm{NO}_{3}^{-}$plays a crucial catalytic in the $\mathrm{Mn}\left(\mathrm{NO}_{3}\right)_{2} / \mathrm{TEMPO} / \mathrm{PyCOOH}$-catalyzed aerobic alcohol oxidation reaction as a source of oxygen activating $\mathrm{NO}_{x}$ species. However, disproportionation of $\mathrm{NO}_{3}{ }^{-}$to the volatile $\mathrm{NO}_{2}$ during the reaction leads to catalyst deactivation under open air conditions. Catalyst deactivation can be overcome by adding a catalytic amount of nitrate salt, for example $\mathrm{NaNO}_{3}$ into the reaction. This stabilizes the $\mathrm{Mn}\left(\mathrm{NO}_{3}\right)_{2} / \mathrm{TEMPO} / \mathrm{PyCOOH}$ catalyst and enables highly selective and near quantitative oxidation of various primary alcohols to the respective aldehydes within few hours under ambient air. The system is also suitable for oxidation of secondary alcohols when catalytic TEMPO is replaced with sterically less hindered nitroxyl radical ABNO. At the end of the alcohol oxidation, pure carbonyl products and reusable catalyst can be separated and recovered simply by extracting with organic solvent and dilute acid, followed by evaporation of both phases.

\section{Experimental Section}

\section{General Information}

All the chemicals used during the work were acquired from commercial sources and used as received. ${ }^{1} \mathrm{H}$ and ${ }^{13} \mathrm{C}$ NMR spectra were recorded on Varian $300 \mathrm{MHz}$ spectrometer. The chemical shifts are reported in parts per million $(\delta)$ relative to TMS $(0 \mathrm{ppm})$. The peak patterns are indicated as follows: $s$ (singlet), $d$ (doublet), $t$ (triplet) q (quartet); dd (doublet of doublets), dt (doublet of triplets), $m$ (multiplet). J-coupling values are reported in Hertz $(\mathrm{Hz})$. Determination of DFF yields during catalyst optimization studies were performed on Agilent 6890N GC system equipped with FID detector using calibration curves with acetophenone as internal standard. Flash column chromatography was performed using $60 \AA$ Å pore size silica gel.

\section{Oxidation of HMF to DFF for catalyst optimization studies}

Oxidation of HMF to DFF presented in figures 1-3 were performed as follows. First, the catalyst solution was prepared by adding a desired amount of $\mathrm{Mn}\left(\mathrm{NO}_{3}\right)_{2} \cdot 4 \mathrm{H}_{2} \mathrm{O}, 2$-picolinic acid, TEMPO, $\mathrm{NaNO}_{3}$ and glacial $\mathrm{AcOH}(2 \mathrm{~mL})$, in this order, to a $30 \mathrm{~mL}$ test tube equipped with a magnetic stirring bar. The resulting solution was stirred in open air for 5 minutes and HMF (126.1 mg, $1.0 \mathrm{mmol}$ ) was then added. The mixture was stirred (800 rpm) at room temperature for desired time, after which the reaction was quenched by adding EtOAc $(10 \mathrm{ml})$.

\section{Conversion and yield determination with GC-FID}

Conversions and yields presented Figures 1-3, as well as conversions in Table 1 were determined as follows. Upon completion, the reaction was quenched by adding EtOAc $(10 \mathrm{ml})$. The mixture was then poured into volumetric flask, internal standard (acetophenone, $200 \mu \mathrm{L}$ ) was added and the solution was diluted to $100 \mathrm{~mL}$ with EtOAc. A sample for GC-analysis was prepared by filtrating an aliquot of $1.5 \mathrm{~mL}$ of the solution through a layer of silica gel $(1 \mathrm{~cm}$ thick). The yields and conversions were determined using GC-FID with calibration curves, (see SI for examples). The reported HMF conversions and DFF yields are average values obtained by performing two parallel reactions and taking two parallel samples from both reactions.

\section{Procedures for alcohol oxidation (Table 1)}

Method A for oxidation of primary alcohols $1 \mathrm{~b}-1 \mathrm{~h}$ : $\mathrm{Mn}\left(\mathrm{NO}_{3}\right)_{2} \cdot 4 \mathrm{H}_{2} \mathrm{O}$ (10.0 mg $0.04 \mathrm{mmol})$, 2-picolinic acid $(7.4 \mathrm{mg} 0.06 \mathrm{mmol})$, TEMPO (6.3 $\mathrm{mg}, 0.04 \mathrm{mmol}), \mathrm{NaNO}_{3}(10.2 \mathrm{mg}, 0.12 \mathrm{mmol})$ and glacial $\mathrm{AcOH}(4 \mathrm{~mL})$ were added, in this order, to a $30 \mathrm{~mL}$ test tube equipped with a magnetic stirring bar. The resulting solution was stirred in open air for 5 minutes and the desired alcohol $(2 \mathrm{mmol})$ was then added. Stirring $(800 \mathrm{rpm})$ was continued at room temperature until the reaction was completed (monitored by TLC). Upon completion, the reaction solution was diluted with diethyl ether $(20 \mathrm{~mL})$, followed by washing with water $(3 \times 10 \mathrm{~mL})$ to remove the catalyst. Aqueous phases were combined and extracted with diethyl ether $(1 \times 10 \mathrm{ml})$. Organic phases were then combined, dried with $\mathrm{MgSO}_{4}$ and evaporated in vacuo to afford carbonyl products. No further purification was performed for $\mathbf{2 b}-\mathbf{2 e}, \mathbf{2 g}$ and $\mathbf{2 h}$. Flash column chromatography was used to purify $\mathbf{2 f}$.

Method B for oxidation of primary alcohols $1 \mathrm{i}-1 \mathrm{k} \mathrm{Mn}\left(\mathrm{NO}_{3}\right)_{2} \cdot 4 \mathrm{H}_{2} \mathrm{O}(10.0$ $\mathrm{mg} 0.04 \mathrm{mmol}$ ), 2-picolinic acid $(7.4 \mathrm{mg} 0.06 \mathrm{mmol})$, TEMPO (6.3 mg, 0.04 $\mathrm{mmol}), \mathrm{NaNO}_{3}(10.2 \mathrm{mg}, 0.12 \mathrm{mmol})$ and glacial $\mathrm{AcOH}(4 \mathrm{~mL})$ were added, in this order, to a $30 \mathrm{~mL}$ test tube equipped with a magnetic stirring bar. The resulting solution was stirred in open air for 5 minutes and cooled down to $16{ }^{\circ} \mathrm{C}$ using water bath fitted with immersion cooler. The desired alcohol ( $2 \mathrm{mmol}$ ) was added and an $\mathrm{O}_{2}$-filled balloon was mounted on top of the reaction. The mixture was stirred $(800 \mathrm{rpm})$ at $16^{\circ} \mathrm{C}$ until the reaction was completed (monitored by TLC). Upon completion, the reaction solution was diluted with diethyl ether $(20 \mathrm{~mL})$, followed by washing with water $(3 \times 10 \mathrm{~mL})$ to remove the catalyst. Aqueous phases were combined and extracted with diethyl ether $(1 \times 10 \mathrm{ml})$. Organic phases were then combined, dried with $\mathrm{MgSO}_{4}$ and evaporated in vacuo to afford crude 2i2k. Flash column chromatography was used to purify the products. 
Method C for oxidation of secondary alcohols 1l-1n: $\mathrm{Mn}\left(\mathrm{NO}_{3}\right)_{2} \cdot 4 \mathrm{H}_{2} \mathrm{O}$ (10.0 mg $0.04 \mathrm{mmol}), 2$-picolinic acid $(7.4 \mathrm{mg} 0.06 \mathrm{mmol})$, ABNO $(2.8 \mathrm{mg}$, $0.02 \mathrm{mmol}), \mathrm{NaNO}_{3}(10.2 \mathrm{mg}, 0.12 \mathrm{mmol})$ and glacial $\mathrm{AcOH}(4 \mathrm{~mL})$ were added, in this order, to a $30 \mathrm{~mL}$ test tube equipped with a magnetic stirring bar. The resulting solution was stirred in open air for 5 minutes and the desired alcohol $(2 \mathrm{mmol})$ was then added. Stirring $(800 \mathrm{rpm})$ was continued at room temperature until the reaction was completed (monitored by TLC). Upon completion, the reaction solution was diluted with diethyl ether $(20 \mathrm{~mL})$, followed by washing with water $(3 \times 10 \mathrm{~mL})$ to remove the catalyst. Aqueous phases were combined and extracted with diethyl ether $(1 \times 10 \mathrm{ml})$. Organic phases were then combined, dried with $\mathrm{MgSO}_{4}$ and evaporated in vacuo to afford ketones $\mathbf{2 1 - 2 n}$. No further purification was required.

\section{Catalyst recycling}

Oxidation of benzyl alcohol for catalyst recycling experiments was conducted according to the following protocol: $\mathrm{Mn}\left(\mathrm{NO}_{3}\right)_{2} \cdot 4 \mathrm{H}_{2} \mathrm{O}(50.2 \mathrm{mg}$ $0.2 \mathrm{mmol}$ ), 2-picolinic acid (36.9 mg $0.3 \mathrm{mmol}$ ), TEMPO (31.3 mg, 0.2 $\mathrm{mmol}), \mathrm{NaNO}_{3}(51.0 \mathrm{mg}, 0.6 \mathrm{mmol})$ and $\mathrm{AcOH}(20 \mathrm{~mL})$ were added, in this order, to a $50 \mathrm{~mL}$ round bottom flask equipped with a magnetic stirring bar. The formed catalyst solution was stirred for five minutes and benzyl alcohol $(1.04 \mathrm{~mL}, 10 \mathrm{mmol})$ was then added. Stirring $(800 \mathrm{rpm})$ was continued at room temperature for $4 \mathrm{~h}$. After completion, the reaction solution was transferred into a separatory funnel, followed by the addition of diethyl ether $(20 \mathrm{~mL})$. The ether solution was then extracted three times with $1 \mathrm{M}$ $\mathrm{HCl}(20 \mathrm{ml}, 10 \mathrm{ml}, 10 \mathrm{ml})$ to transfer the catalyst into aqueous phase. The aqueous phases were combined, washed with diethyl ether $(10 \mathrm{ml})$ and evaporated in vacuo to afford the recovered catalyst as dark green solid. Prior to subsequent run, fresh $\mathrm{NaNO}_{3}(85.0 \mathrm{mg}, 1.0 \mathrm{mmol})$ and glacial $\mathrm{AcOH}(20 \mathrm{ml})$ were added on top of the catalyst and the formed mixture was stirred for $5 \mathrm{~min}$. New reaction was then initiated by adding benzyl alcohol $(1.04 \mathrm{ml}, 10 \mathrm{mmol})$. Note: the recycled catalyst should be dried under oil pump vacuum until the color changes from yellow to dark green. The use of wet catalyst leads to hampered reactivity.

\section{Acknowledgements}

We thank Kjell Knapas for his help in the preparation of the manuscript and we are grateful for funding from the Academy of Finland.

Keywords: oxidation $\cdot$ alcohols $\cdot$ manganese $\cdot$ synthetic methods

[1] M. Hudlicky, Oxidations in Organic Chemistry, American Chemical Society, Washington, DC, DC, 1990.

[2] E. J. Corey, J. W. Suggs, Tetrahedron Lett. 1975, 16, 2647-2650.

[3] G. Piancatelli, A. Scettri, M. D’Auria, Synthesis (Stuttg). 1982, 1982, 245-258.

[4] A. J. Fatiadi, Synthesis (Stuttg). 1976, 1976, 65-104

[5] R. J. K. Taylor, M. Reid, J. Foot, S. A. Raw, Acc. Chem. Res. 2005, 38, 851-869.

[6] D. B. Dess, J. C. Martin, J. Org. Chem. 1983, 48, 4155-4156.

[7] M. Uyanik, K. Ishihara, Chem. Commun. 2009, 2086-2099.

[8] K. E. Pfitzner, J. G. Moffatt, J. Am. Chem. Soc. 1963, 85, 3027-
3028.

[9] A. J. Mancuso, D. S. Brownfain, D. Swern, J. Org. Chem. 1979, 44, 4148-4150.

[10] T. T. Tidwell, Synthesis (Stuttg). 1990, 1990, 857-870.

[11] R. M. Hazen, L. W. Finger, J. Castex, J. Peyronneau, A. E. Ringwood, T. Suzuki, M. Akaogi, T. G. Sharp, A. El Goresy, B. Wopenka, et al., Science (80-. ). 2000, 287, 1636-1639.

[12] B. A. Steinhoff, S. R. Fix, S. S. Stahl, J. Am. Chem. Soc. 2002, 124, 766-767.

[13] B.-Z. Zhan, M. A. White, T.-K. Sham, J. A. Pincock, R. J. Doucet, K. V. R. Rao, K. N. Robertson, T. S. Cameron, J. Am. Chem. Soc. 2003, 125, 2195-2199.

[14] I. E. Markó, A. Gautier, R. Dumeunier, K. Doda, F. Philippart, S. M. Brown, C. J. Urch, Angew. Chemie Int. Ed. 2004, 43, 1588-1591.

[15] J. Piera, J.-E. Bäckvall, Angew. Chemie Int. Ed. 2008, 47, 35063523.

[16] J. E. Steves, S. S. Stahl, J. Am. Chem. Soc. 2013, 135, 1574215745.

[17] P. Lucio Anelli, C. Biffi, F. Montanari, S. Quici, J. Org. Chem. 1987, 52, 2559-2562.

[18] P. L. Anelli, S. Banfi, F. Montanari, S. Quici, J. Org. Chem. 1989, 54, 2970-2972.

[19] M. Shibuya, M. Tomizawa, I. Suzuki, Y. Iwabuchi, J. Am. Chem. Soc. 2006, 128, 8412-8413.

[20] M. Shibuya, M. Tomizawa, Y. Sasano, Y. Iwabuchi, J. Org. Chem. 2009, 74, 4619-4622.

[21] M. Hayashi, Y. Sasano, S. Nagasawa, M. Shibuya, Y. Iwabuchi, Chem. Pharm. Bull. 2011, 59, 1570-1573.

[22] T. F. Blackburn, J. Schwartz, J. Chem. Soc. Chem. Commun. 1977, 157-158.

[23] K. P. Peterson, R. C. Larock, J. Org. Chem. 1998, 63, 3185-3189.

[24] T. Nishimura, T. Onoue, K. Ohe, S. Uemura, Tetrahedron Lett. 1998, 39, 6011-6014.

[25] G.-J. ten Brink, I. W. C. E. Arends, R. A. Sheldon, Adv. Synth. Catal. 2002, 344, 355-369.

[26] R. Tang, S. E. Diamond, N. Neary, F. Mares, J. Chem. Soc. Chem. Commun. 1978, 562

[27] M. Matsumoto, S. Ito, J. Chem. Soc. Chem. Commun. Commun. 1981, 17, 907-908.

[28] J.-E. Backvall, R. L. Chowdhury, U. Karlsson, J. Chem. Soc. Chem. Commun. 1991, 473-475.

[29] A. Dijksman, I. W. C. E. Arends, R. A. Sheldon, Chem. Commun. 1999, 1591-1592.

[30] L. Prati, M. Rossi, J. Catal. 1998, 176, 552-560.

[31] A. Abad, P. Concepción, A. Corma, H. García, Angew. Chemie Int. Ed. 2005, 44, 4066-4069.

[32] C. Della Pina, E. Falletta, L. Prati, M. Rossi, Chem. Soc. Rev. 2008, 37, 2077-2095.

[33] C. Della Pina, E. Falletta, M. Rossi, Chem. Soc. Rev. 2012, 41, 350-369.

[34] H. Wang, W. Fan, Y. He, J. Wang, J. N. Kondo, T. Tatsumi, J. Catal. 2013, 299, 10-19.

[35] J. F. Greene, J. M. Hoover, D. S. Mannel, T. W. Root, S. S. Stahl, Org. Process Res. Dev. 2013, 17, 1247-1251. 
[36] A. Gavriilidis, A. Constantinou, K. Hellgardt, K. K. (Mimi) Hii, G. J. Hutchings, G. L. Brett, S. Kuhn, S. P. Marsden, React. Chem. Eng. 2016, 1, 595-612.

[37] A. Hanyu, E. Takezawa, S. Sakaguchi, Y. Ishii, Tetrahedron Lett. 1998, 39, 5557-5560.

[38] N. Wang, R. Liu, J. Chen, X. Liang, Chem. Commun. 2005, 53225324.

[39] D. J. C. Constable, P. J. Dunn, J. D. Hayler, G. R. Humphrey, J. Leazer Johnnie L., R. J. Linderman, K. Lorenz, J. Manley, B. A. Pearlman, A. Wells, et al., Green Chem. 2007, 9, 411-420. W. Yin, C. Chu, Q. Lu, J. Tao, X. Liang, R. Liu, Adv. Synth. Catal. 2010, 352, 113-118.

[41] E. Takezawa, S. Sakaguchi, Y. Ishii, Org. Lett. 1999, 1, 713-715.

[42] P. M. Osterberg, J. K. Niemeier, C. J. Welch, J. M. Hawkins, J. R. Martinelli, T. E. Johnson, T. W. Root, S. S. Stahl, Org. Process Res. Dev. 2015, 19, 1537-1543.

[43] G. Tojo, M. Fernández, Oxidations of Alcohols to Aldehydes and Ketones - A Guide to Current Common Practice, Springer, New York, 2006 G. Tojo, M. Fernández, Oxidation of Primary Alcohols to Carboxylic Acids - A Guide to Current Common Practice, Springer-Verlag, New York, 2007.

C. Bilgrien, S. Davis, R. S. Drago, J. Am. Chem. Soc. 1987, 109, 3786-3787.

6] K. Kaneda, T. Yamashita, T. Matsushita, K. Ebitani, J. Org. Chem. 1998, 63, 1750-1751. A. T. Radosevich, C. Musich, F. D. Toste, J. Am. Chem. Soc. 2005, 127, 1090-1091.

M. S. Sigman, D. R. Jensen, Acc. Chem. Res. 2006, 39, 221-229.

N. R. Conley, L. A. Labios, D. M. Pearson, C. C. L. McCrory, R. M. Waymouth, Organometallics 2007, 26, 5447-5453.

Z. Du, H. Miao, H. Ma, Z. Sun, J. Ma, J. Xu, Adv. Synth. Catal. 2009, 351, 558-562.

M. F. Semmelhack, C. R. Schmid, D. a. Cortés, C. S. Chou, J. Am. Chem. Soc. 1984, 106, 3374-3376. Commun. (Camb). 2003, 2414-5.

[53] P. J. P. J. Figiel, A. Sibaouih, J. U. Ahmad, M. Nieger, M. T. T Räisänen, M. Leskelä, T. Repo, Adv. Synth. Catal. 2009, 351, 2625-2632.

[54] E. T. T. Kumpulainen, A. M. P. Koskinen, Chem. - A Eur. J. 2009, 15, 10901-10911.
Y. Sasano, S. Nagasawa, M. Yamazaki, M. Shibuya, J. Park, Y. Iwabuchi, Angew. Chemie Int. Ed. 2014, 53, 3236-3240.

S. Ma, J. Liu, S. Li, B. Chen, J. Cheng, J. Kuang, Y. Liu, B. Wan, Y. Wang, J. Ye, et al., Adv. Synth. Catal. 2011, 353, 1005-1017. L. Wang, S. Shang, G. Li, L. Ren, Y. Lv, S. Gao, J. Org. Chem. 2016, 81, 2189-2193.

K. Lagerblom, P. Wrigstedt, J. Keskiväli, A. Parviainen, T. Repo, Chempluschem 2016, 81, 1160-1165.

K. Lagerblom, E. Lagerspets, J. Keskiväli, C. Cook, F. Ekholm, A Parviainen, T. Repo, ChemCatChem 2017, 9, 3880-3887.

J. N. Chheda, Y. Roman-Leshkov, J. A. Dumesic, Green Chem. 2007, 9, 342-350.

B. Saha, S. Dutta, M. M. Abu-Omar, Catal. Sci. Technol. 2012, 2, $79-81$.

J. Artz, S. Mallmann, R. Palkovits, ChemSusChem 2015, 8, 672679.

P. Wrigstedt, J. Keskivali, T. Repo, RSC Adv. 2016, 6, 1897318979.

A. Gandini, M. N. Belgacem, Prog. Polym. Sci. 1997, 22, 12031379.

K. T. Hopkins, W. D. Wilson, B. C. Bender, D. R. McCurdy, J. E. Hall, R. R. Tidwell, A. Kumar, M. Bajic, D. W. Boykin, J. Med. Chem. 1998, 41, 3872-3878.

C. Moreau, M. N. Belgacem, A. Gandini, Top. Catal. 2004, 27, 1130.

A. Gandini, Green Chem. 2011, 13, 1061-1083.

J. Ma, Z. Du, J. Xu, Q. Chu, Y. Pang, ChemSusChem 2011, 4, 5154.

C. Aellig, C. Girard, I. Hermans, Angew. Chemie Int. Ed. 2011, 50, 12355-12360.

[7] Y. Kameoka, R. L. Pigford, Ind. Eng. Chem. Fundam. 1977, 16, 163-169.

B. J. Finlayson-Pitts, L. M. Wingen, A. L. Sumner, D. Syomin, K. A. Ramazan, Phys. Chem. Chem. Phys. 2003, 5, 223-242.

L. C. Grotz, J. Chem. Educ. 1973, 50, 63.

G. Svehla, in Vogel's Qual. Inorg. Anal., Addison Wesley Longman Ltd, Essex, 1996, p. 177.

G. D. Mendenhall, K. U. Ingold, J. Am. Chem. Soc. 1973, 95, 63956400. 


\section{WILEY-VCH}

\section{FULL PAPER}

Entry for the Table of Contents (Please choose one layout)

Layout 1:

\section{FULL PAPER}

Text for Table of Contents

Layout 2:

\section{FULL PAPER}

Author(s), Corresponding Author(s)*

Page No. - Page No.

Title width: $5.5 \mathrm{~cm}$; max. height: $5.0 \mathrm{~cm}$ ))

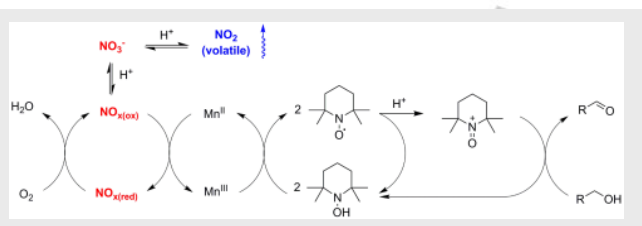

Aerobic oxidation of alcohols with homogenous $\mathrm{Mn} / \mathrm{nitroxyl}$ radical-based catalyst is investigated. The study presents findings on catalyst stability and its deactivation mechanisms as well as shows that catalyst deactivation can be overcome by adding small amount of nitrate ions into the reaction. The nitrate stabilized catalyst enables straightforward, highly practical and selective oxidation of various alcohols to aldehydes and ketones under mild conditions.
K. Lagerblom, J. Keskiväli, Dr. A. Parviainen, J. Mannisto and Prof. Dr. T. Repo*

Page No. - Page No.

Title 